\title{
Reunión anual de Swets en Barcelona
}

\author{
Por Núria Sauri
}

Resumen: Resumen de las novedades presentadas en el ya tradicional congreso anual de usuarios de Swets celebrado el 4 de junio de 2009 en Barcelona: la aplicación SwetsWise Selection Support, el portal de prensa PressDisplay, la Alpsp Learned Journals Collection, y la plataforma de distribución de libros-e MyiLibrary. Se está disparando la venta de libros-e.

Palabras clave: Swets, Reunión de usuarios, SwetsWise, Selection Support, Sistema de ayuda a la decisión, PressDisplay, Alpsp, ALJC, MyiLibrary, Libros-e.

Title: Swets annual user meeting in Barcelona

Abstract: Summary of developments presented D the traditional annual congress of Swets users held on June 4, 2009 in Barcelona: the tool SwetsWise Selection Support, PressDisplay news portal, the

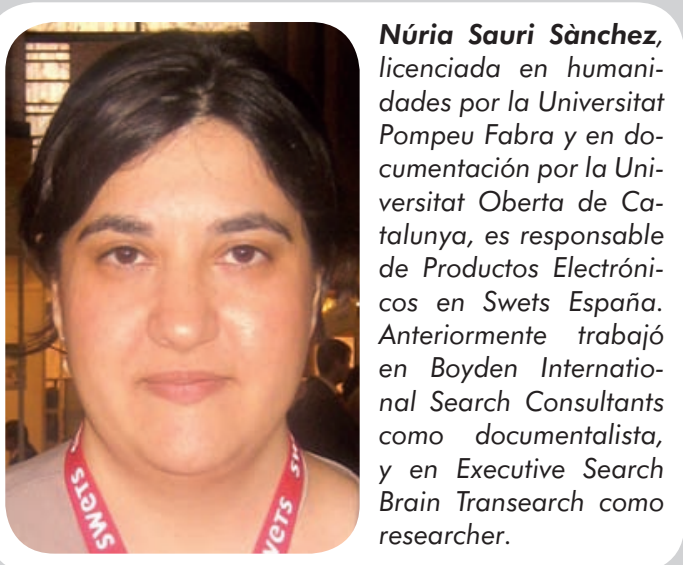
ALPSP Learned Journals Collection, and the e-book platform MyiLibrary. e-Books sales are soaring.

Keywords: Swets, User meeting, SwetsWise, Selection Support, Decision support system, PressDisplay, Alpsp, ALJC, MyiLibrary, e-Books.

Sauri, Núria. "Reunión anual de Swets en Barcelona". El profesional de la información, 2009, julio-agosto, v. 18, n. 4, pp.466-469.

DOI: $10.3145 /$ epi.2009.jul.17

\section{EL PASADO 4 DE JUNIO} SWETS celebró su congreso anual con sus clientes. Este evento se realiza alternativamente en Madrid y Barcelona y en 2009 el lugar escogido fue la Casa de Convalescència del Hospital de Sant Pau.

Dirk Lens, director de la Región Sur, analizó el mercado actual de suscripciones y productos electrónicos. "Afrontamos tiempos de incertidumbre debido a la situación económica actual y Swets es consciente de que esto afecta a muchos de sus clientes. Por eso, la política de Swets siempre ha sido trabajar junto con los clientes, intentando ser flexibles y adaptarse a sus necesidades para poder preservar la integridad de las colecciones, evitando en lo posible que se produzcan cortes en las suscripciones".

\section{SwetsWise Selection Support}

De todas maneras, si la reducción de presupuestos en las bibliotecas tiene que afectar a las suscrip-

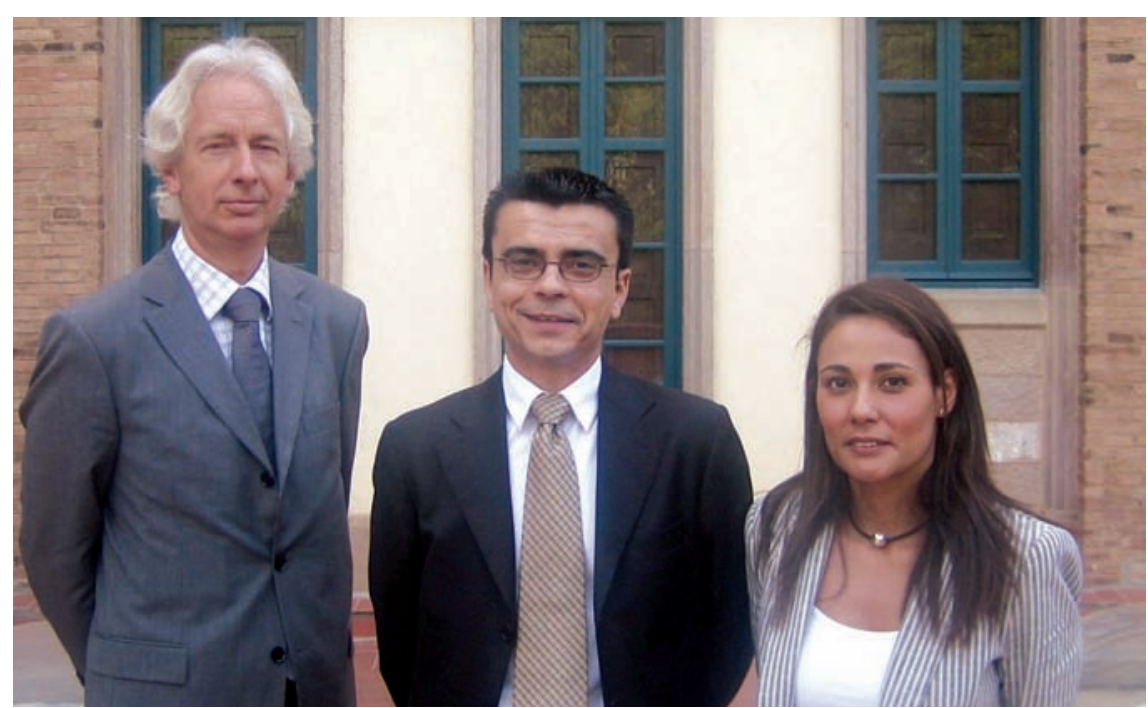

Dirk Lens (director Swets Sur Europa), Juan-Carlos Martín-González (director Swets España) y Laura Bonald (ejecutiva en Sevilla)

ciones, Swets acaba de lanzar Selection Support, una herramienta de apoyo a la toma de decisiones que combina las estadísticas de uso e información de los precios. De esta manera las bibliotecas obtienen automáticamente el indicador "coste por uso" (coste de la suscripción dividido por el número de artículos consultados por los usuarios), así como un análisis de tendencias a lo largo de un período. Esto es una gran ayuda para evaluar el interés de cada título.

SwetsWise Selection Support combina los datos de la plataforma ScholarlyStats para recopilar las estadísticas de uso con la información de precios almacenada en SwetsWise Suscriptions. 


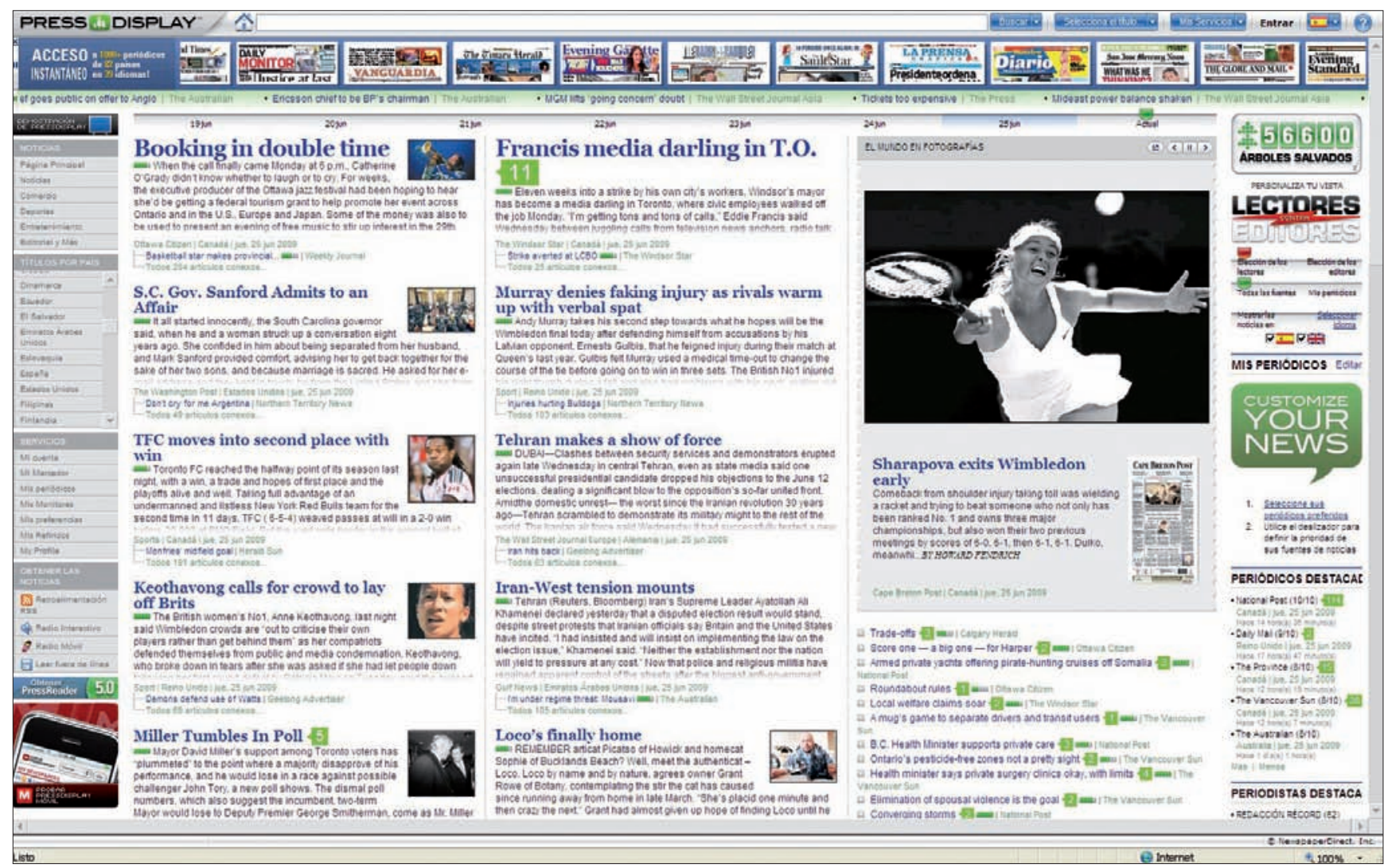

http://www.pressdisplay.com

Es de destacar que el sistema ofrece recolección automática de estadísticas de uso de otras plataformas de revistas definidas por el cliente, sean suscritas vía Swets o a través de otro proveedor. Además, es posible añadir manualmente información de cualquier otra suscripción para poder disponer de una visión completa de toda la colección.

Los informes pueden ser tanto en formato Counter (Counting Online Usage of Networked Electronic Resources), como personalizados.

http://www.projectcounter.org/ about.html

\section{PressDisplay}

Presentado por Manuel Mendo, este portal de periódicos online ofrece más de 900 publicaciones de 83 países en 39 idiomas, que se muestran en su formato y diseño original, incluido el texto completo y las imágenes.

De España sólo tiene $A B C$ y $L a$ vanguardia, por lo que su interés es sobre todo por su gran variedad de prensa extranjera. Con este producto las bibliotecas pueden servir a unos usuarios que cada vez tienen orígenes más diversos, pero también resulta ideal para grandes empresas, que suelen tener un servicio de news clipping para estar informados de su presencia en prensa extranjera y para seguir temas de su interés.

PressDisplay va acompañado de servicios de valor añadido:

- Conversor simultáneo de texto a voz.

- Traductor de los artículos del idioma original del periódico a 10 idiomas (entre ellos español e inglés).

- Marcar y enviar artículos por e-mail.

- Visualizar las páginas en miniaturas.

- Búsqueda por palabras, títulos, autores, etc.

No necesita ningún tipo de soft- ware adicional para la instalación ni ningún tipo de descarga.

\section{"Productos como \\ PressDisplay y ALJC \\ demuestran la vitalidad de esta empresa centenaria de extender su oferta más allá de las tradicionales suscripciones de revistas por las cuales es famosa"}

\section{ALJC}

La Alpsp Learned Journals Collection (ALJC) de la Association of Learned and Professional Society Publishers (Alpsp) es ofrecida por Swets en exclusiva. Laura Bonald recordó el proceso de gestación de esta peculiar y extraordinaria colección:

Alpsp es una asociación de editores sin ánimo de lucro creada en 


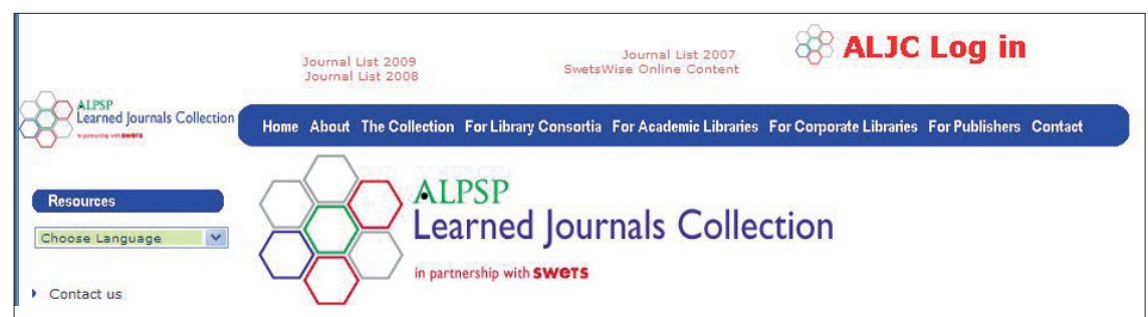

http://aljc.swets.com/

el Reino Unido en 1972. Actualmente tiene más de 360 miembros en 36 países.

En varios encuentros entre miembros los pequeños editores manifestaron su inquietud por el impacto que los big deals tenían en los presupuestos de las bibliotecas y por la dificultad que para ellos entrañaban las ventas consorciadas (no quedaba dinero para ellos).

Al mismo tiempo las bibliotecas tenían las mismas dificultades para mantener títulos importantes pertenecientes a esos pequeños editores. De ahí surgió la idea de crear un paquete que reuniese revistas de esos pequeños editores miembros de Alpsp bajo una única licencia (un big deal para esa asociación). En 2003 Alpsp convocó un concurso para la realización del proyecto y adjudicó a Swets la puesta en marcha de la colección.

La colección de 2009 contiene 774 revistas de 49 editores, que se venden como una única licencia con un precio del paquete garantizado durante 3 años. Esto permite a las bibliotecas mantener títulos que en otras circunstancias podrían ser cancelados debido a restricciones de presupuesto. Este contrato baja notablemente el precio medio por revista.

En España 15 universidades han adquirido ya $A L J C$, así como el consorcio SELL (South European Library Link), de bibliotecas del Sur de Europa, independientemente del país en el que se encuentran las instituciones miembro. $C B U C$ (Consorcio de Bibliotecas Universitarias de Catalunya) se ha encargó de la coordinación del acuerdo, que se firmó en 2007 y va a ser renovado de cara a 2010.

Dado el buen recibimiento de ALJC, Swets y Alpsp han decidido distribuir también una colección de 1.200 títulos de e-books de 15 editores a través de la plataforma $M y i$ Library.

Swets conoce bien todo lo que implica el paso de papel a electrónico, y por tanto está preparada para comercializar e-books con las máximas garantías, ya que la empresa tiene una experiencia proverbial en la gestión y negociación de recursos electrónicos [recuérdense los proyectos National Electronic Site Licence Initiative (Nesli), en el Reino Unido; y el del consorcio

HEAL-Link de 57 universidades griegas].

http://aljc.swets.com/

http://www.alpsp.org/

Juan-Carlos Martín, “country manager" de Swets España, centró su intervención en los modelos de adqusición de e-books, y cómo estos modelos de adquisición afectan al desarrollo de las colecciones. "Cuando hablamos de e-books, hay que tomar una serie de decisiones (agregador $v s$ editor, paquete $v s$ pick and choose (elegir cada título suelto), acceso perpetuo vs suscripción...)

Swets cubre todas las posibilidades de compra, y asesora a los clientes para que la decisión que tomen sea la más adecuada. Por ejemplo, cuando se trata de decidir entre un editor o un agregador, las bibliotecas deben tener en cuenta si prefieren comprar colecciones completas o un modelo pick and choose, en cuyo caso un agregador sería la opción más interesante.

\section{MyiLibrary}

Este agregador de Ingram Digital, fue presentado por Estíbaliz Castresana. Una nueva interfaz entró en funcionamiento el día 10 de junio, desglosándose así la que sirve para buscar y acceder al contenido:

\section{http://lib.myilibrary.com}

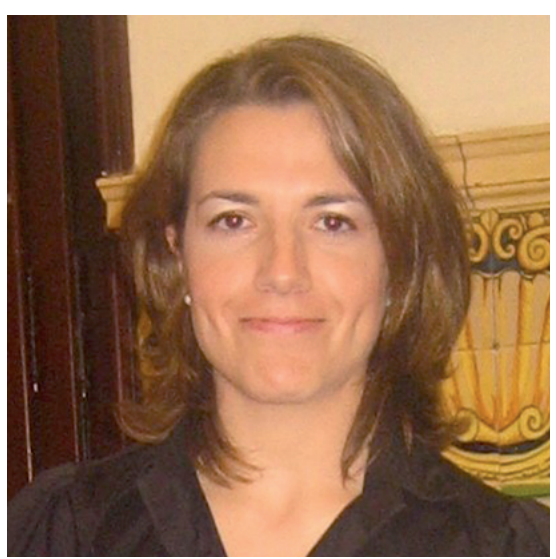

Estíbaliz Castresana

http://www.myilibrary.com/

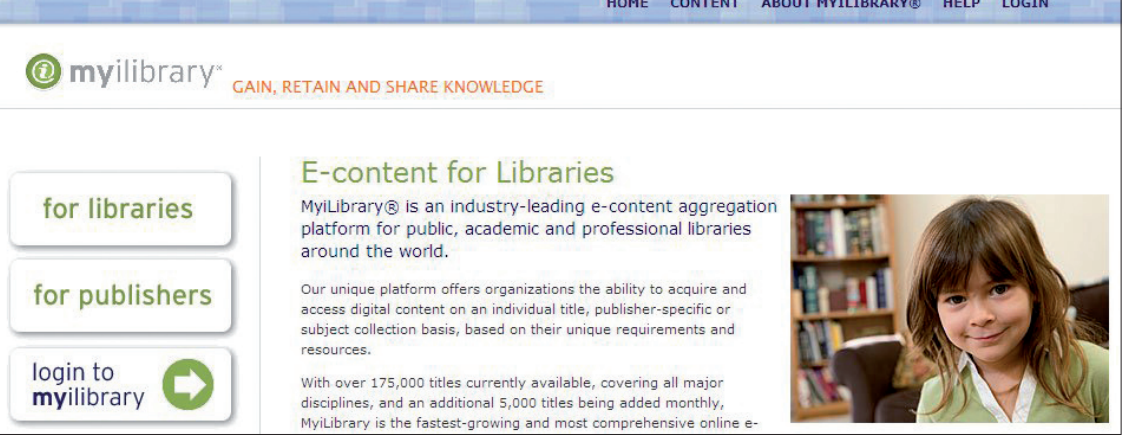

With over 175,000 titles currently available, covering all major disciplines, and an additional 5,000 titles being added monthly,

E-content for Libraries Mylibrary@ is an industry-leading e-content aggrega platform for public, academic and professional libraries

for publishers

login to

myilibrary
HOME CONTENT ABOUT MYILIBRARY@ HELP LOGIN 
de otra que es usada por el administrador:

http://www.myilibrary.com

MyiLibrary es un agregador que contiene 175.000 títulos de elibros, de ellos muchos en exclusiva. Permite buscar en texto completo en toda la plataforma a la vez, así como en los metadatos. Se trata del único agregador de e-books que cumple con los requisitos Counter, $\mathrm{y}$ es plenamente compatible con SwetsWise Selection Support.

\section{Preservación digital}

Como ponente especial, esta vez se contó con Alice Keefer, profesora de la Facultad de Biblioteconomía y Documentación de la Universitat de Barcelona: Como es sabido, el almacenamiento de datos en formato digital tiene el gran problema de que no solamente hay que preservar los datos, sino también los soportes. Un fallo en el servidor puede causar pérdidas de información.

Keefer presentó varias soluciones para preservar recursos digitales, como Portico, Clockss y e-depot. Se trata de dark archives (archivos oscuros) que permiten acceso al material guardado en el caso de los llamados trigger events (desaparición del editor, disconti- nuidad de la revista, desaparición del archivo histórico, destrucción de servidores, etc.).

Para cerrar el acto, tuvo lugar una comida conjunta en el Aula Magna de la Casa de Convalescècia del Hospital de Sant Pau.

Swets anunció que el próximo congreso se celebrará en Madrid en junio de 2010.

Núria Sauri, Swets, Nàpols $2272 a$ pl., 08013 Barcelona.

Tel.: +34-932081 970; Móv.: +34620984185

nsauri@es.swets.com

http://www.swets.com

lis-epi

\section{Valencia, 26-27 de noviembre de 2009 "Prospectiva de la información en 2015"}

\section{Organizado por:}

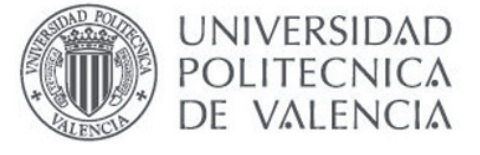

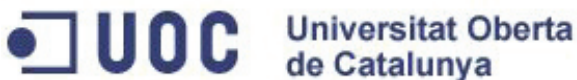
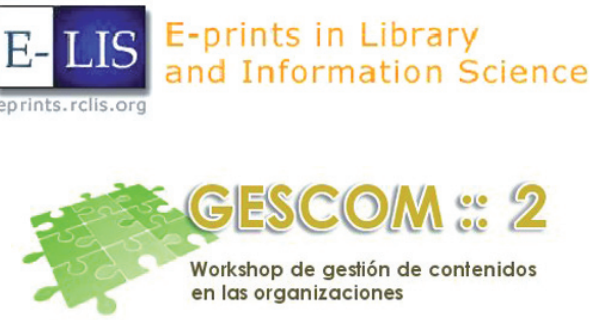

El profesional de la información

\section{Patrocinado por:}

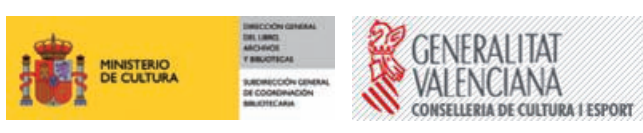

